\title{
Catheter-Associated Bacteria Urinary Tract Infection and Antibiotic Susceptibility Pattern in a Tertiary Hospital, in Ghana
}

\author{
Edwin Mwintiereh Ta-ang Yenli1,2*, Jacob Nii Otinkorang Ankrah ${ }^{3,4}$, David Eklu Zeyeh5, \\ Juventus Benogle Ziem6
}

\author{
${ }^{1}$ Department of Surgery, School of Medicine and Health Sciences, University for Development Studies, Tamale, Ghana \\ ${ }^{2}$ Urology Unit, Tamale Teaching Hospital, Tamale, Ghana \\ ${ }^{3}$ Department of Biomedical Sciences, School of Allied Health Science, University for Development Studies, Tamale, Ghana \\ ${ }^{4}$ Microbiology Unit, Tamale Central Hospital, Tamale, Ghana \\ ${ }^{5}$ Microbiology Unit, Tamale Teaching Hospital, Tamale, Ghana \\ ${ }^{6}$ Deparment of Clinical Microbiology, School of Medicine and Health Sciences, University for Development Studies, Tamale, Ghana \\ Email: ^mwintyus@yahoo.com, ankrahjake@gmail.com, zdondavid@gmail.com, jbziem@yahoo.com
}

How to cite this paper: Yenli, E.M.T., Ankrah, J.N.O., Zeyeh, D.E. and Ziem, J.B. (2019) Catheter-Associated Bacteria Urinary Tract Infection and Antibiotic Susceptibility Pattern in a Tertiary Hospital, in Ghana. Open Journal of Urology, 9, 140-151. https://doi.org/10.4236/oju.2019.99017

Received: June 16, 2019

Accepted: September 16, 2019

Published: September 19, 2019

Copyright $\odot 2019$ by author(s) and Scientific Research Publishing Inc. This work is licensed under the Creative Commons Attribution International License (CC BY 4.0).

http://creativecommons.org/licenses/by/4.0/

\begin{abstract}
Background: This study seeks to identify the prevalence of catheter associated urinary infection and the type of bacteria that are associated with this infection, as well as the antibiotic susceptibility patterns of the organisms isolated. This would guide the choice of antibiotics when there is catheter associated urinary tract infection. Method: From 1 November 2015-31 April 2016 a cross-sectional study was conducted among patients with urinary catheter in-situ. Urine samples collected were processed and cultured on CLED agar plates. Pure colonies of isolated organism were Gram and Biochemically characterized. A disc diffusion antibiotic susceptibility determined by Kirby-Bauer disc diffusion method was performed on each uropathogen isolated. Data obtained was cleaned, analyzed and presented. Result: There were 122 study subjects of which, 73 (59.8\%) were males and 49 (40.2\%) were females. Their median age was 42.5 (range 33 - 65) years. Significant bacterial growth was obtained in $88(72.1 \%)$ of the urine specimen cultured of which males constituted $48(54.5 \%)$ and females $40(45.5 \%)$. The most prevalent uropathogens isolated were Escherichia coli 41 (46.6\%), Klebsiella spp. 18 (20.6\%), Pseudomonas aeruginosa 10 (11.4\%), Enterobacter spp. 6 (6.8\%) and Staphylococcus aureus 5 (5.8\%). Bacterial isolates showed some susceptibility to Amikacin 73 (83.0\%), Levofloxacin 34 (38.6\%) and Ciprofloxacin 26 (29.5\%) respectively. The uropathogens were least susceptible to Gentamicin 3 (3.4\%), Ampicillin 3 (3.4\%) and Cefuroxime 1 (1.1\%) respectively. Conclusion: Catheter associated bacterial urinary tract infection (CABUTI) is prevalent at
\end{abstract}


the Tamale Teaching Hospital. Micro bacterial isolates demonstrated substantial decrease in susceptibility to antibiotics commonly used. Understanding the local antibiotic susceptibility pattern could guide the choice of antibiotics used in treating CABUTI.

\section{Keywords}

Catheter Bacteria Urinary Tract Infection

\section{Introduction}

Urinary catheters are passed to permit drainage of urine [1]. They may have diagnostic or therapeutic uses [2]. Globally, about two-thirds of urinary tract catheterization among adults is for therapeutic reasons in order to relief bladder outlet obstruction due to benign prostatic obstruction [3] [4] [5] [6]. The risk of bacterial Urinary Tract Infections (UTI) is dependent on the patient's susceptibility, the quality of catheter and how long catheter has been in place [7] [8].

Catheter Associated Bacteria Urinary Tract Infection (CABUTI) occurs in at least $40 \%$ of hospital-acquired infections [9]. CABUTI has been associated with substantial morbidity in acute care settings and extended care facilities at rates of $20 \%$ and $50 \%$ respectively [8]. CABUTI rates vary widely from up to $5 \%$ for single brief catheterization to $100 \%$ for indwelling catheters over a duration of 4 days [10]. Female, advanced age and the critically ill are known risk factors [11].

In clinical practice, varied microorganisms may be associated with CABUTI and these include: Escherichia coli, Klebsiella spp., Proteus, Enterococci, Pseudomonas, Enterobacter, Serratia and Candida [12] [13]. Within a couple of days after insertion of catheter, bacteria may migrate to bladder from biofilms formed on the surface of indwelling catheter [14] [15]. Commonly, biofilms are initially caused by a single species of bacteria and may eventually become polymicrobial and resistant to various antimicrobial agents especially following long-term catheterization [16] [17]. Worldwide, antimicrobial resistance due to CABUTI contributes substantially to a rise in morbidity and mortality as well as high cost of health care delivery. The epidemiology remains variable and health facility dependent [18].

Understanding the local antibiotic susceptibility pattern in our setting could enable practitioners to select the appropriate medication necessary for effective treatment. Therefore, this study was carried out to determine the prevalence of CABUTI and the antimicrobial susceptibility pattern at Tamale Teaching Hospital.

\section{Methods}

\subsection{Study Type}

This is a cross-sectional study conducted among patients who had catheter in- 
serted into urinary bladder from November 2015 to April 2016.

\subsection{Study Site}

Tamale Teaching Hospital, an 800 bed capacity tertiary hospital in Tamale, Northern Region, Ghana.

\subsection{Patients' Recruitment and Specimen Collection}

From November 2015 to April 2016, a cross sectional study was undertaken at the urology clinic of the Tamale Teaching Hospital of Ghana. The eligibility criteria included patients who had catheter in situ and who consented to be part of the study. We excluded, immunosuppressed patients, non-catheterized patients, those who had confirmed UTI just preceding this study, those taking antibiotic prophylaxis prior to catheterization and those who declined consent.

Eligible patients who consented to be part of the study were assigned unique Identification (Id) numbers. Data was recorded on a well-designed sheet. Data fields included: age, sex, address marital status and indication for catheterization.

A spigot was placed at tip of catheter and opened when the patient experienced the sensation to void, associated with a suprapubic mass, which was indicative of a full bladder. The spigot was then removed to allow about $10-20 \mathrm{ml}$ of urine to flow through and drop off. This was to ensure clean urine was obtained devoid of contamination. Urine collection was done under aseptic conditions into a sterile, dry, leak-proof container. About $2-5 \mathrm{ml}$ was collected from the tip of catheter. The containers were labeled with the patient's identification number, age, sex, date and the time of collection. The urine specimen was transported together with the data collection form and delivered to the bacteriology laboratory for culture, biochemical tests, isolation and antibiotic susceptibility tests.

Using a sterile calibrated wire loop and under aseptic conditions, about $0.01 \mathrm{ml}$ of urine was inoculated onto a prepared agar plate of Cystine Lactose Electrolyte Deficient (CLED). The plate was incubated under aerobic conditions at $37^{\circ} \mathrm{C}$ for 24 hours and observed for bacteria growth. Significant growth of $>10^{5}$ bacte$\mathrm{ria} / \mathrm{ml}$ of catheter urine was interpreted as a colony of bacteria with a viable count [19]. Bacteria colonies were identified using colony growth characteristics and Gram staining as well as standard biochemical testing procedures which included indole, urea, triple sugar Iron (TSI), motility and citrate tests were all carried out in accordance with Monica Chessbrough [20].

An emulsification was made in bijou bottle containing $5 \mathrm{ml}$ peptone water with the pure colonies, until the turbidity was equal to the $0.5 \mathrm{McF}$ arland standards. An approximately $200 \mu \mathrm{l} /$ loopful of the suspension was dispensed to the center of $25 \mathrm{ml}$ Muller-Hinton culture plate and seeded carefully with the sterile swab stick in three directions to obtain even growth on the Muller-Hinton agar surface, allowing the moisture to be absorbed for at least 15minutes. Using the disc diffusion method of antimicrobial susceptibility test, the urine antibiotics multi-discs (manufactured by Axiom Laboratories, India) were applied firmly to 
the surface of the Mueller-Hinton agar plate. The antibiotics multidisc comprised of Ampicillin (AMP, $20 \mathrm{mcg}$ ), Ceftizoxime (CL, $30 \mathrm{mcg}$ ), Ciprofloxacin (CP, $\mathrm{mcg}$ ), Amikacin (AMK, $30 \mathrm{mcg}$ ), Cotrimoxazole (BA, $25 \mathrm{mcg}$ ), Cephalexin (PR, $30 \mathrm{mcg}$ ), Tetracycline (TE, $30 \mathrm{mcg}$ ), Levofloxacin (LE, $5 \mathrm{mcg}$ ), Ofloxacin (OF, 5 $\mathrm{mcg}$ ), Norfloxacin (NX, $10 \mathrm{mcg})$, Chloramphenicol (CH, $30 \mathrm{mcg})$, Sparfloxacin (SC, $5 \mathrm{mcg}$ ), Gentamicin (GEN, $30 \mathrm{mcg}$ ), Ceftriaxone (CTR, $30 \mathrm{mcg}$ ), Cefuroxime (30 mcg).

The set-up was incubated aerobically at $37^{\circ} \mathrm{C}$ for $18-24 \mathrm{hrs}$, after which it was inspected for bacteria growth and growth inhibition. The diameter of the zone of growth inhibition around each antimicrobial agent was measured and compared with the NCCLS interpretive table, NCCLS, 1997 to determine bacterial sensitivity or resistance to each of the antimicrobial agents used [21]. Standard commercial bacteria strains comprising of Staphylococcus aureus NCTC 6571, Escherichia coli NCTC 10418 and Pseudomonas aeruginosa NCTC 10662 were used as control.

Data was entered into Microsoft excel spreadsheet windows 7 and checked for data entry errors. Data analysis was carried out using IBM SPSS version 21 statistical package. Associations between variables were determined with level of significance set at $\mathrm{p}<0.05$.

\section{Results}

One hundred and twenty-two patients participated in the study. There were 73 (59.8\%) males and 49 (40.2\%) females. The median age was 42.5 (range 33 - 65) years. There were $37(30.3 \%)$ participants in the modal age group $51-60$ years (Table 1). The highest number of bacterial isolates $22(25.0 \%)$ out of the 88 positive culture results were in age group 31 - 40 years. Frequency of urine culture isolates and age were not statistically significant $(\mathrm{p}=0.35)$ (Table 2$)$.

Significant bacterial growth was obtained in $88(72.1 \%)$ of the urine sample cultured, of which males constituted $48(54.5 \%)$ and females 40 (45.5\%). This was not statistically significant $(\mathrm{p}=0.06)$. The relationship between sensitivity

Table 1. The socio-demographic characteristics of patients with catheter $(n=122)$.

\begin{tabular}{ccc}
\hline \multirow{2}{*}{ Age Group } & \multicolumn{2}{c}{ Gender $\mathbf{N}=\mathbf{1 2 2}$} \\
\cline { 2 - 3 }$\leq 20$ & Female Frequency (\%) & Male Frequency (\%) \\
$21-30$ & $1(0.8)$ & $2(1.6)$ \\
$31-40$ & $8(6.5)$ & $7(5.7)$ \\
$41-50$ & $8(6.5)$ & $2(1.6)$ \\
$51-60$ & $10(8.2)$ & $12(9.8)$ \\
$61-70$ & $18(14.8)$ & $19(15.6)$ \\
$71-80$ & $2(1.6)$ & $9(7.4)$ \\
$81-90$ & $2(1.6)$ & $15(12.3)$ \\
$91-100$ & 0 & $6(4.9)$ \\
& 0 & $1(0.8)$ \\
& $49(40.2)$ & $73(59.8)$ \\
\hline
\end{tabular}


Table 2. Urine culture results among various age groups.

\begin{tabular}{cccc}
\hline \multirow{2}{*}{ Age Group } & Urine Culture & \multirow{2}{*}{$\chi^{2}(\mathrm{df})$} & P-value \\
\cline { 2 - 3 } & Frequency (\%) $\mathbf{N}=\mathbf{8 8}$ & $8.94(8)$ & 0.35 \\
$21-30$ & $2(2.3)$ & & \\
$31-40$ & $9(10.2)$ & \\
$41-50$ & $22(25.0)$ & \\
$51-60$ & $17(19.3)$ & \\
$61-70$ & $11(12.5)$ & \\
$71-80$ & $8(9.1)$ & \\
$81-90$ & $12(13.6)$ & \\
$91-100$ & $6(6.8)$ & \\
\hline
\end{tabular}

df: degrees of freedom.

pattern of bacteria to antibiotics and sex category of the patient was not significant $(\mathrm{p}=0.06)$.

Thirteen different organisms were identified from 88 (72.1\%) culture positives of which 81 (92.1\%) were Gram-negative bacteria, 6 (6.8\%) Gram-positive bacteria and in $1(1.1 \%)$ case of Candida albicans was isolated. The predominant bacteria isolates were Escherichia (E.) coli 41 (46.6\%), Klebsiella spp. 18 (20.6\%), Pseudomonas spp. 10 (11.4\%), Enterobacter 6 (6.8\%) and Staphylococcus aureus 5 (5.8\%). Other organisms isolated 8 (8.8\%) include: Citrobacterdiversus, morgani, Enterococcus spp., Klebsiellaoxytoca, Streptococcus spp., Proteus mirabilis and Candida albicans (Table 3).

All isolates demonstrated sensitivity to Amikacin. Pseudomonas aeroginosa demonstrated the least sensitivity to Amikacin (70\%) while Enterobacter spp. and Staphylococcus aureus were the most sensitive (100\%). Gentamycin and cefuroxime showed the least sensitivity pattern; as they were sensitive to only one isolate each of Escherichia coli. The remaining drugs on the antibiotics multidisc showed variable sensitivity pattern (Table 4).

Among the isolates, the best sensitivity pattern to majority of the antimicrobials was observed for Escherichia coli. Escherichia coli isolates demonstrated sensitivity to Amikacin 35 (85.4\%), Levofloxacin 17 (41.5\%) and Ciprofloxacin 16 (39\%) in descending order. None of the isolates was susceptible to Ampicillin. Klebsiella spp. 15 (83.3\%) exhibited sensitivity to Amikacin but resistant to Ampicillin, Gentamicin, Cefuroxime and Cephalexin (Table 4).

Generally, the best susceptibility of bacteria isolates to antibiotics was observed in the following antimicrobials: Amikacin 73 (83.0\%), Levofloxacin 34 (38.6\%), Ciprofloxacin 26 (29.5\%), Ceftizoxime 23 (26.1\%), Orfloxacin 22 (25.0\%) and Chloramphinicol 21 (23.9\%) respectively in descending order. Overall, decreased susceptibility of bacteria to antibiotics was observed with Sparfloxacin 13 (14.8\%), Cephalexin 8 (9.1\%), Norfloxacin 7 (8.0\%), Cotrimoxazole 7 (8.0\%), Gentamicin 3 (3.4\%), Ampicillin 3 (3.4\%) and Cefuroxime 1 (1.1\%), respectively (Table 5). 
Table 3. Pattern of uropathogens isolated.

\begin{tabular}{cc}
\hline Organisms & $\begin{array}{c}\text { Number of Samples of uropathogens isolated (N = 88) } \\
\text { Frequency (\%) }\end{array}$ \\
\hline Escherichia coli & $41(46.6)$ \\
Klebsiella spp. & $18(20.6)$ \\
Pseudomonas aeruginosa & $10(11.4)$ \\
Enterobacter spp. & $7(8.0)$ \\
Staphylococcus aureus & $5(5.8)$ \\
Citrobacter diversus & $1(1.1)$ \\
Morganella morgani & $1(1.1)$ \\
Proteus vulgaris & $1(1.1)$ \\
Klebsiella oxytoca & $1(1.1)$ \\
Streptococcus spp. & $1(1.1)$ \\
Proteus mirabilis & $1(1.1)$ \\
Candida albicans & $1(1.1)$ \\
Total & $\mathbf{8 8}(100)$
\end{tabular}

Table 4. Antimicrobial susceptibility patterns to most common bacterial isolates.

\begin{tabular}{|c|c|c|c|c|c|c|c|c|c|c|}
\hline \multirow{3}{*}{$\begin{array}{l}\text { Antibiotic } \\
\text { Sensitivity }\end{array}$} & \multicolumn{10}{|c|}{ Bacteria Isolates } \\
\hline & \multicolumn{2}{|c|}{$\begin{array}{c}\text { E. coli } \\
(\mathrm{n}=41)\end{array}$} & \multicolumn{2}{|c|}{$\begin{array}{l}\text { Klebsiella spp. } \\
\qquad(\mathrm{n}=18)\end{array}$} & \multicolumn{2}{|c|}{$\begin{array}{c}\text { Pseudomonas } \\
\text { aeroginosa }(\mathrm{n}=10)\end{array}$} & \multicolumn{2}{|c|}{$\begin{array}{l}\text { Enterobacter } \\
\operatorname{spp} .(\mathrm{n}=4)\end{array}$} & \multicolumn{2}{|c|}{$\begin{array}{c}\text { Staphylococcus } \\
\text { aureus }(\mathrm{n}=5)\end{array}$} \\
\hline & $\mathrm{N}$ & $\% \mathrm{~N}$ & $\mathrm{~N}$ & $\% \mathrm{~N}$ & $\mathrm{~N}$ & $\% \mathrm{~N}$ & $\mathrm{~N}$ & $\% \mathrm{~N}$ & $\mathrm{~N}$ & $\% \mathrm{~N}$ \\
\hline Ampicillin & 0 & 0.0 & 0 & 0.0 & 0 & 0.0 & 0 & 0.0 & 1 & 20.0 \\
\hline Ceftizoxime & 16 & 39.0 & 4 & 22.2 & 2 & 20.0 & 1 & 25.0 & 0 & 0.0 \\
\hline Ciprofloxacin & 16 & 39.0 & 4 & 22.2 & 4 & 40.0 & 1 & 25.0 & 1 & 20.0 \\
\hline Amikacin & 35 & 85.4 & 15 & 83.3 & 7 & 70.0 & 4 & 100 & 5 & 100 \\
\hline Cotrimoxazole & 3 & 7.3 & 1 & 5.6 & 1 & 10.0 & 1 & 25.0 & 1 & 20.0 \\
\hline Cephalexin & 7 & 17.1 & 0 & 0.0 & 0 & 0.0 & 0 & 0.0 & 1 & 20.0 \\
\hline Ofloxacin & 13 & 31.7 & 5 & 27.8 & 2 & 20.0 & 0 & 0.0 & 2 & 40.0 \\
\hline Norfloxacin & 3 & 7.3 & 3 & 16.7 & 0 & 0.0 & 1 & 25.0 & 0 & 0.0 \\
\hline Chloramphenicol & 10 & 24.4 & 5 & 27.8 & 4 & 40.0 & 1 & 25.0 & 0 & 0.0 \\
\hline Sparfloxacin & 8 & 19.5 & 3 & 16.7 & 1 & 10.0 & 0 & 0.0 & 1 & 20.0 \\
\hline Gentamicin & 1 & 2.4 & 0 & 0.0 & 0 & 0.0 & 0 & 0.0 & 0 & 0.0 \\
\hline Cefuroxime & 1 & 2.4 & 0 & 0.0 & 0 & 0.0 & 0 & 0.0 & 0 & 0.0 \\
\hline Levofloxacin & 17 & 41.5 & 7 & 38.9 & 4 & 40.0 & 2 & 50.0 & 3 & 60.0 \\
\hline
\end{tabular}


Table 5. Overall susceptibility of uropathogens.

\begin{tabular}{ccc}
\hline & \multicolumn{3}{c}{ Sensitivity of Isolate } \\
N $=88$ \\
\cline { 2 - 3 } Antibiotics & Frequency & $(\%)$ \\
\hline Amikacin & 73 & $(83.0)$ \\
Levofloxacin & 34 & $(38.6)$ \\
Ciprofloxacin & 26 & $(29.5)$ \\
Ceftizoxime & 23 & $(26.1)$ \\
Ofloxacin & 22 & $(25.0)$ \\
Chloramphenicol & 21 & $(23.9)$ \\
Sparfloxacin & 13 & $(14.8)$ \\
Cephalexin & 8 & $(9.1)$ \\
Norfloxacin & 7 & $(8.0)$ \\
Cotrimoxazole & 7 & $(8.0)$ \\
Gentamicin & 3 & $(3.4)$ \\
Ampicillin & 3 & $(3.4)$ \\
Cefuroxime & 1 & $(1.1)$ \\
\hline
\end{tabular}

\section{Discussion}

The prevalence of CABUTI and antimicrobial susceptibility patterns among patients may vary from one setting to the other. In the United Kingdom, Wazait and associate found catheter associated urinary tract infection to be $35.5 \%$. Koshariya and colleagues reported the prevalence of CABUTI in India to be $27 \%$ [22]. In Nigeria, Taiwo et al. reported the prevalence of CABUTI of $13.3 \%$ and 98.8\% when bladder catheter was in situ at less than 7 days or more than 7 days respectively [23]. In this study, the prevalence of CABUTI was $72.1 \%$. This could be due to contamination of urine by bowel flora or catheters were passed without adherence to strict aseptic protocols. Also, this high prevalence may be due to prolonged catheterization as the duration of catheterization prior to sample collection was not established by this study. Among females, the prevalence of CABUTI was $45.5 \%$. There exist anatomical variations, between female and male urethra and meatus. The female urethra is short and has a meatus closer to the anal opening. This poses a risk for females to contract CABUTI.

\subsection{CABUTI Uropathogens Identification}

Urine culture test has been used over decades for diagnosing patients who have UTI. The identification of CABUTI uropathogens and the antibiotic susceptibility patterns enable practitioners select the appropriate antibiotics for treatment. Escherichia coli, the leading uropathogen in urine cultures and other Enterobacteriaceae, account for approximately $75 \%$ of all uropathogens [24] [25] [26]. Included in the top five uropathogens were Escherichia coli 30.5\%, Klebsiella 
pneumoniae 30.5\%, Pseudomonas aeruginosa $16.6 \%$ and Candida spp. $16.6 \%$ as reported by Kazi and colleaques [27]. This present study revealed that Escherichia coli 46.6\%, Klebsiella spp. 20.6\%, Pseudomonas spp. 11.4\%, Enterobacter $6.8 \%$ and Staphylococcus aureus $5.8 \%$ respectively were the most prevalent CABUTI uropathogens at the Tamale Teaching Hospital. The least prevalent CABUTI uropathogens were Citrobacter diversus, Morganella morgani, Enterococcus spp., Klebsiellao xytoca, Streptococcus spp., Proteus mirabilis and Candida albicans each constituting 1 (1.1\%). These organisms are mainly endogenous bowel flora. Thus, poor personal hygiene or non-adherence to aseptic technique during catheterization could account for the higher prevalence of these organisms in the urine of our study participants. It has been established that CABUTI is one of the health care associated infections that may be contracted through contact with contaminated equipment or solutions and from other patients or hospital staff [23] [28] [29].

\subsection{Uropathogen Antibiotics Susceptibility}

Antibiotic use by patients prior to presentation of urine samples could significantly alter microbial yield and consequently prediction of infection rates because they suppress the endogenous bacteria flora [30] [31]. Multiple studies have demonstrated resistance to a host of antibiotics including ampicillin, chloramphenicol, cotrimoxazole, gentamicin, cefuroxime [30] [32] [33]. This phenomenon of drug resistance differs from one place to another. Though there is antimicrobial resistance to a large extend, some studies show there were susceptibility of uropathogens to some antibiotics. In Ghana, Gyansa-Lutterodt and associates found high susceptibility of uropathogens to Nitrofuantoin and Gentamicin at the Police Hospital, while Gyasi-Sarpong et al reported susceptibility of uropathogens to ciprofloxacin, nalidixic acid, cefuroxime, ceftriaxone and cefotaxime at the Komfo Anokye Teaching Hospital [30] [32]. In order of decreasing susceptibility, we report that Amikacin 83.0\%, Levofloxacin 38.6\% and Ciprofloxacin $29.5 \%$ were the antibiotics found to be most suitable in treatment of urinary tract infection at the Tamale Teaching Hospital. The existence of substantial resistance of bacterial isolates to antibiotics is therefore implied. This might be as a result of indiscriminate usage of these antibiotics resulting in resistance among the bacterial isolates. The bacterial isolates showed least susceptibility to Cefuroxime 1.1\%, Ampicillin 3.4\% and Gentamicin 3.4\% in order of increasing susceptibility. Other antibiotics with least sensitivity were Co-trimoxazole $8.0 \%$, Norfloxacin 8.0\%, Cephalexin 9.1\%, Sparfloxacin 14.8\%, Chloramphenicol $23.9 \%$ and Ofloxacin $25.0 \%$ in order of increasing susceptibility. It is important for practicing clinicians to appraise their knowledge on the local antibiotics' susceptibility patterns so as to effectively treat CABUTI.

This study had some limitations. Firstly, the duration of catheterization preceding sample collection for urine culture and sensitivity was not established. Secondly, the participants were not grouped into either catheter associated bac- 
teriuria (asymptomatic) and catheter associated urinary tract infection (symptomatic). For catheter associated bacteriuria (asymptomatic), no treatment is usually needed. This is an important point to consider in determining antibiotic susceptibility and recommending treatment.

\section{Conclusion}

Catheter-associated bacterial urinary tract infection is prevalent at the Tamale Teaching Hospital. Micro bacterial isolates demonstrated substantial decrease in susceptibility to antibiotics commonly used. Understanding the local antibiotic susceptibility pattern could guide the choice of antibiotics used in treating catheter-associated bacterial urinary tract infection.

\section{Acknowledgements}

The authors are grateful to the Head of Department of the Tamale Teaching Hospital Laboratory for providing the laboratory space towards this work.

\section{Conflicts of Interest}

The authors declare no conflicts of interest regarding the publication of this paper.

\section{References}

[1] Ortega, R., Ng, L., Sekhar, P. and Song, M. (2008) Female Urethral Catheterization. The New England Journal of Medicine, 358, e15. https://doi.org/10.1056/NEJMvcm0706671

[2] Cravens, D.D. and Zweig, S. (2000) Urinary Catheter Management. American Family Physician, 61, 369-376.

[3] Yenli, E.M.T., Aboah, K., Gyasi-Sarpong, C.K., Azorliade, R. and Arhin, A.A. (2015) Acute and Chronic Urine Retention among Adults at the Urology Section of the Accident and Emergency Unit of Komfo Anokye Teaching Hospital, Kumasi, Ghana. African Journal of Urology, 21, 129-136. https://doi.org/10.1016/j.afju.2014.08.009 http://www.sciencedirect.com/science/article/pii/S1110570415000193

[4] Fitzpatrick, J.M., Desgrandchamps, F., Adjali, K., Gomez Guerra, L., Hong, S.J., El Khalid, S., et al. (2012) Management of Acute Urinary Retention: A Worldwide Survey of 6074 Men with Benign Prostatic Hyperplasia. BJU International, 109, 88-95. https://doi.org/10.1111/j.1464-410X.2011.10430.x

[5] Desgrandchamps, F., De La Taille, A. and Doublet, J.-D. (2006) The Management of Acute Urinary Retention in France: A Cross-Sectional Survey in 2618 Men with Benign Prostatic Hyperplasia. BJU International, 97, 727-733.

https://doi.org/10.1111/j.1464-410X.2006.06109.x

[6] Elhilali, M., Vallancien, G., Emberton, M., Alcaraz, A., Harving, N., Moorselaar, J.V., et al. (2004) 225 Management of Acute Urinary Retention (AUR) in Patients with BPH: A Worldwide Comparison. European Urology Supplements, 3, 59. https://doi.org/10.1016/S1569-9056(04)90226-6 https://www.eusupplements.europeanurology.com/article/S1569-9056(04)90226-6/a $\underline{\text { bstract }}$ 
[7] Blodgett, T.J., Gardner, S.E., Blodgett, N.P., Peterson, L.V. and Pietraszak, M. (2015) A Tool to Assess the Signs and Symptoms of Catheter-Associated Urinary Tract Infection: Development and Reliability. Clinical Nursing Research, 24, 341-356. https://doi.org/10.1177/1054773814550506 http://www.ncbi.nlm.nih.gov/pmc/articles/PMC4369445

[8] Nicolle, L.E. (2014) Catheter Associated Urinary Tract Infections. Antimicrobial Resistance and Infection Control, 3, 23. https://doi.org/10.1186/2047-2994-3-23

[9] Rüden, H., Gastmeier, P., Daschner, F.D. and Schumacher, M. (1997) Nosocomial and Community-Acquired Infections in Germany. Summary of the Results of the First National Prevalence Study (NIDEP). Infection, 25, 199-202.

https://doi.org/10.1007/BF01713142 https://link.springer.com/article/10.1007/BF01713142

[10] Stark, R.P. and Maki, D.G. (1984) Bacteriuria in the Catheterized Patient. New England Journal of Medicine, 311, 560-564. https://doi.org/10.1056/NEJM198408303110903

[11] Garibaldi, R.A., Burke, J.P., Dickman, M.L. and Smith, C.B. (1974) Factors Predisposing to Bacteriuria during Indwelling Urethral Catheterization. The New England Journal of Medicine, 291, 215-219. https://doi.org/10.1056/NEJM197408012910501

[12] Jacobsen, S.M., Stickler, D.J., Mobley, H.L.T. and Shirtliff, M.E. (2008) Complicated Catheter-Associated Urinary Tract Infections Due to Escherichia coli and Proteus mirabilis. Clinical Microbiology Reviews, 21, 26-59. https://doi.org/10.1128/CMR.00019-07

[13] Pappas, P.G., Kauffman, C.A., Andes, D., Benjamin, D.K., Calandra, T.F., Edwards, J.E., et al. (2009) Clinical Practice Guidelines for the Management of Candidiasis: 2009 Update by the Infectious Diseases Society of America. Clinical Infectious Diseases, 48, 503-535. https://doi.org/10.1086/596757

[14] Donlan, R.M. (2001) Biofilm Formation: A Clinically Relevant Microbiological Process. Clinical Infectious Diseases, 33, 1387-1392. https://doi.org/10.1086/322972

[15] Saint, S. and Chenoweth, C.E. (2003) Biofilms and Catheter-Associated Urinary Tract Infections. Infectious Disease Clinics of North America, 17, 411-432. https://doi.org/10.1016/S0891-5520(03)00011-4

[16] Peters, B.M., Jabra-Rizk, M.A., O’May, G.A., Costerton, J.W. and Shirtliff, M.E. (2012) Polymicrobial Interactions: Impact on Pathogenesis and Human Disease. Clinical Microbiology Reviews, 25, 193-213. https://doi.org/10.1128/CMR.00013-11

[17] Carson, C. and Naber, K.G. (2004) Role of Fluoroquinolones in the Treatment of Serious Bacterial Urinary Tract Infections. Drugs, 64, 1359-1373. https://doi.org/10.2165/00003495-200464120-00007

[18] Clec'h, C., Schwebel, C., Français, A., Toledano, D., Fosse, J.-P., Garrouste-Orgeas, M., et al. (2007) Does Catheter-Associated Urinary Tract Infection Increase Mortality in Critically Ill Patients? Infection Control \& Hospital Epidemiology, 28, 1367-1373. https://doi.org/10.1086/523279

[19] Warren, J.W. (1997) Catheter-Associated Urinary Tract Infections. Infectious Disease Clinics of North America, 11, 609-622. https://doi.org/10.1016/S0891-5520(05)70376-7

[20] Cheesbrough, M. (2006) Microbiological Tests. In: District Laboratory Practice in Tropical Countries, Cambridge University Press, New York, 1-266. https://doi.org/10.1017/CBO9780511543470.002

[21] Gentilini, E., Denamiel, G., Betancor, A., Rebuelto, M., Rodriguez Fermepin, M. and De Torres, R.A. (2002) Antimicrobial Susceptibility of Coagulase-Negative Staphy- 
lococci Isolated from Bovine Mastitis in Argentina. Journal of Dairy Science, 85, 1913-1917. http://www.sciencedirect.com/science/article/pii/S0022030202742677 https://doi.org/10.3168/jds.S0022-0302(02)74267-7

[22] Koshariya, M., Songra, M.C., Namdeo, R., Chaudhary, A., Agarwal, S. and Rai, A. (2015) Prevalence of Pathogens and Their Antimicrobial Susceptibility in Catheter Associated Urinary Tract Infection. International Archives of Integrated Medicine, 2, 96-113.

[23] Taiwo, S.S. and Aderounmu, A.O.A. (2006) Catheter Associated Urinary Tract Infection: Aetiologic Agents and Antimicrobial Susceptibility Pattern in Ladoke Akintola University Teaching Hospital, Osogbo, Nigeria. African Journal of Biomedical Research, 9, 141-148. https://doi.org/10.4314/ajbr.v9i3.48897

[24] Prakash, D. and Saxena, R.S. (2013) Distribution and Antimicrobial Susceptibility Pattern of Bacterial Pathogens Causing Urinary Tract Infection in Urban Community of Meerut City, India. ISRN Microbiology, 2013, Article ID: 749629.

https://doi.org/10.1155/2013/749629

[25] Ayoade, F., Moro, D.D. and Ebene, O.L. (2013) Prevalence and Antimicrobial Susceptibility Pattern of Asymptomatic Urinary Tract Infections of Bacterial and Parasitic Origins among University Students in Redemption Camp, Ogun State, Nigeria. Open Journal of Medical Microbiology, 3, 219-226.

https://doi.org/10.4236/ojmm.2013.34033

[26] Rizvi, M., Khan, F., Shukla, I., Malik, A. and Shaheen (2011) Rising Prevalence of Antimicrobial Resistance in Urinary Tract Infections during Pregnancy: Necessity for Exploring Newer Treatment Options. Journal of Laboratory Physicians, 3, 98-103. http://www.ncbi.nlm.nih.gov/pmc/articles/PMC3249726 https://doi.org/10.4103/0974-2727.86842

[27] Kazi, M.M., Harshe, A., Sale, H. and Mane, D.Y.M. (2015) Catheter Associated Urinary Tract Infections (CAUTI) and Antibiotic Sensitivity Pattern from Confirmed Cases of CAUTI in a Tertiary Care Hospital: A Prospective Study. Clinical Microbiology, 4, Article ID: 1000193.

[28] Beale, A.J., McLeod, D.L., Stackiw, W. and Rhodes, A.J. (1958) Isolation of Cytopathogenic Agents from the Respiratory Tract in Acute Laryngotracheobronchitis. British Medical Journal, 1, 302-303. https://doi.org/10.1136/bmj.1.5066.302 http://www.ncbi.nlm.nih.gov/pmc/articles/PMC2027557

[29] Selden, R., Lee, S., Wang, W.L., Bennett, J.V. and Eickhoff, T.C. (1971) Nosocomial Klebsiella Infections: Intestinal Colonization as a Reservoir. Annals of Internal Medicine, 74, 657-664. https://doi.org/10.7326/0003-4819-74-5-657

[30] Gyasi-Sarpong, C.K., Nkrumah, B., Yenli, E.M.T., Appiah, A.A., Aboah, K., Azorliade, R., et al. (2014) Resistance Pattern of Uropathogenic Bacteria in Males with Lower Urinary Tract Obstruction in Kumasi, Ghana. African Journal of Microbiology Research, 8, 3324-3329.

http://www.academicjournals.org/journal/AJMR/article-abstract/172730647457

[31] Afriyie, D.K., Gyansa-Lutterodt, M., Amponsah, S.K., Asare, G., Wiredu, V., Wormenor, E., et al. (2015) Susceptibility Pattern of Uropathogens to Ciprofloxacin at the Ghana Police Hospital. Pan African Medical Journal, 22, 87. https://doi.org/10.11604/pamj.2015.22.87.6037

[32] Gyansa-Lutterodt, M., Afriyie, D.K., Asare, G., Amponsah, S.K., Abutiate, H. and Darko, D. (2014) Antimicrobial Use and Susceptibility Pattern of Uropathogens Associated with Urinary Tract Infections at the Ghana Police Hospital. Global Journal of Pharmacology, 8, 306-315. 
[33] Newman, M.J., Frimpong, E., Donkor, E.S., Opintan, J.A. and Asamoah-Adu, A. (2011) Resistance to Antimicrobial Drugs in Ghana. Infection and Drug Resistance, 4, 215-220. http://www.ncbi.nlm.nih.gov/pmc/articles/PMC3259688 